\title{
Patient Safety: Perception among Medical Students of Tanta Faculty of Medicine, Egypt
}

\author{
Shimaa M. Saied, Abdelaziz F. Aldeib, and Noha M. Elghazally
}

Public Health and Community Medicine Department Tanta Faculty of Medicine, Tanta University, Egypt

Received: January, 2016 Accepted: April, 2016

\begin{abstract}
Background: Patient safety became a global health issue to insure high quality health care services and with minimal medical errors. WHO developed Patient Safety Curriculum Guide for Medical Schools to be used as a requisite in medical curricula standard. Objectives: to assess medical students' perception as regard patient safety issues and to find out their opinions towards its inclusion in the medical curricula. Methodology: A descriptive cross-sectional study was executed at Tanta faculty of medicine for 3 months using self-administered questionnaire for $5^{\text {th }}, 6^{\text {th }}$ years' students and house officers. Students' self-ratings of knowledge and attitude towards patient safety were measured, and their opinion about its inclusion into curriculum was described. Results: 418 participants were included in the study, $85.2 \%$ of them had no previous training on patient safety \& $57.2 \%$ of them had an average total self-rated knowledge level. $53.1 \%$ had a positive attitude toward patient safety, a majority agreed that patient safety is a global problem \& $86.4 \%$ of them admit that teaching patient safety issues in medical curriculum is a priority. Conclusion: The study revealed deficient perception of medical students regarding patient safety issues, and demonstrated the urgent need of its inclusion into medical curricula.
\end{abstract}

Keywords: Patient safety; Perception; Attitude; Medical students; Tanta

Corresponding author: Shimaa M. Saied e-mail: Dr.Shimaasaied@gmail.com

\section{Introduction}

Significant improvement occurred in healthcare because of advances in medical science and technology, unfortunately this improvement has a drawback on patient safety, as patients suffer increasingly from adverse events resulting from hospitalization and medical management. Patient safety has emerged because of this matter as a distinct health care discipline that could help health team to develop a patient safety culture. ${ }^{1}$ WHO defines patient safety as "the reduction of risk of unnecessary harm associated with healthcare to an acceptable minimum". ${ }^{2}$ Usually, medical errors accuse personal aspects and attribute these to human factors like forgetfulness, carelessness, poor motivation, and negligence. This approach excuses the establishments from any responsibility. Conversely, the "systems approach" is based upon the hypothesis that humans will make errors even in the best of institutions. Actually, carelessness related to weaknesses in the defense system including factors like time pressure, understaffing, sleep deprivation, prolonged duty hours, and their subsequent physical, emotional, and mental fatigue. So the solution lies in improving the working environment or the system defense as the important matter is how and why the system defenses failed, but is not about who 
did. $^{3,4}$ In spite of increased concern of patient safety and healthcare quality, adverse outcomes and medical errors are still frequent in clinical practice. Although it is difficult to obtain a valid estimate of errors, there is now an international consensus that $10 \%$ of hospitalized patients suffer injuries related to medical management and at least half of the adverse events are preventable. $^{5-7}$

In developed countries, which has sufficient funds and modern technology, one out of ten patients is injured, while in developing countries, the burden of unsafe care is still unclear; where inadequate infrastructure, technology, and insufficient or even unskillful human resources caused higher possible risk of injury to the hospitalized patients and in primary care settings compared to developed countries. ${ }^{8}$ In health care systems in high income countries up to $18 \%$ of hospitalized patients are harmed due to medical errors. ${ }^{9}$

Assessment of current safety culture in a healthcare organization is the first step to identify the most problematic areas for improvement, since healthcare staff knowledge, attitudes and pattern of behaviors are critical in the promotion of the workplace climate needed to secure an organizational culture of safety. ${ }^{10-13}$

A study in Pakistan, 2015 concluded the existence of significant knowledge gap among medical students as regards patient safety concerns. The teaching of patient safety was greatly supported by students, and required to be included in the medical curriculum urgently. ${ }^{14}$ Another study in Italy, 2012 found that Physicians' knowledge of evidencebased safety practices was inconsistent, while positive attitudes about patient safety were revealed by the responders. ${ }^{15}$ Positive attitudes related to patient safety issues are also present among health care professionals in Lithuania. ${ }^{16}$ Iranian medical and paramedical students, 2015 were aware about medical errors as an inevitable barrier between the best care and the actually provided one. However, there was little knowledge about the multi-factorial mechanisms underlying occurrence of errors. ${ }^{17}$

Culture of safety, which is an effective strategy for sustainable safety improvement, is highly encouraged by the major health organizations such as the WHO, National Patient Safety Foundation (NPSF), the Joint Commission International (JCI) and the Institute for Health Care Improvement (IHI) with the following standard patient safety goals: identify patients correctly, use medicines safely, prevent infection, identify patient safety risks, improve staff communication, use alarms safely, and decrease the risks of patient falls. ${ }^{18}$

Modern studies have highlighted the requirement for patient safety education to begin throughout medical school, in order to assist change the culture of medicine in addition to integrate medical students into the health care team. ${ }^{18}$ WHO developed a standard curriculum guide to be used in preparation of patient safety courses for teaching in medical schools; it includes the following topics: What is patient safety?, What is human factors and why is it important to patient safety?, Understanding systems and the impact of complexity on patient care, Being an effective team player, Understanding and learning from errors, Understanding and managing clinical risk, Introduction to quality improvement methods, engaging with patients and carers, Introduction to cluster, putting knowledge into practice, Minimizing infection through improved infection control, Patient safety and invasive procedures, and lastly improving medication safety. ${ }^{1}$

The current mainstream medical curriculum in Tanta faculty of medicine does not contain any topics regarding patient safety, but in the new Competency-based Medical Bachelor Program (CBMBP) a patient safety 
course is included. Due to paucity of the available adequate data concerning this topic in Egypt, the current study was executed to assess medical students' perceptions regards patient safety issues and to test their opinions towards the endorsement of the patient safety educational issues into the undergraduate and postgraduate curricula.

\section{Methods:}

Study design, settings, and sampling:

This cross-sectional study was conducted during the period from $1^{\text {st }}$ October to the end of December in the academic year 2016 among medical students including undergraduates students in the fifth \& sixth grades, and house officers, at Tanta Medical College and Tanta university Hospital through convenience sampling. Students in the fifth \& sixth grades were selected for this survey because they had finished their basic medical knowledge courses and began to receive clinical education and training. House officers were also selected because they completed their clinical education, and began their practical training, they are easily accessible, and relatively have time to fill the questionnaire than residents. The sample size was calculated as 384 participants using Epi info 7, based on $50 \%$ expected outcome, and 95\% confidence level, with an error bound of 0.05 (precision). The sample size was increased by $15 \%$ for better accuracy and validity. 450 questionnaires were distributed, and 420 returned with response rate $93.33 \%$ and 12 questionnaires were excluded because of incomplete data. Inclusion Criteria were: $5^{\text {th }}$, and $6^{\text {th }}$ grade medical students, and house officers willing to give consent \& complete the questionnaire. Exclusion Criteria were: other students not in the specified grades and student in specified graded not willing to give a consent \& complete the questionnaire.

\section{Data collection and instruments (study} tool): A pre-tested self-administered valid and reliable structured questionnaire, it was developed by researchers based on previous studies, it was used to assess awareness regarding patient safety, and to test opinions towards its inclusion into undergraduate and postgraduate curricula. Participants were provided the questionnaire by researchers and requested to fill it after a brief explanation of the purpose of the study and taking their consent. The questionnaire includes diverse types of questions about patient safety. The first section composed of questions concerning demographic characteristics: gender, age, grade or academic level, whether received any previous training regarding patient safety \& where he received. The second section consisted of ten questions about awareness including Patient safety goals, different types of medical error, factors contributing to it, awareness of its adverse outcomes, factors influencing patient safety, how to report an error, understanding and managing clinical risk. These tool items were graded into: "Low=0, Medium=1, and Good=2" knowledge. A total knowledge percent score was calculated; $<50 \%$ was considered as "poor" knowledge, $50-75 \%$ was considered "Average" knowledge, and > 75\% was considered "Good" knowledge. The third section composed of fifteen items regarding attitude from its all aspects. It was rated on (3) Likert scale "Agree=2", "neutral=1", and "disagree=0", and attitude percent score was calculated as a percentage of the maximum possible score; < 50\% was considered as "Negative" attitude, and $\geq 50 \%$ was considered "Positive" attitude. The fourth section enclosed ten items related to participants` opinion for including patient safety in the medical curricula, training on it, how to report \& its importance.

Data management and analysis: Microsoft Excel 2013 was used to input all the data, which were then coded, 
analyzed using, Statistical Package for Social Sciences software, version 21.0 (SPSS Inc., Chicago, IL). Descriptive results were expressed as frequency, percentage, and mean \pm S.D. $P$-values < 0.05 were accepted as statistically significant. Pearson chi-square was used to test for significant relationships between categorical variables.

Ethical considerations: The purpose of the study was explained to all participants. Participants' consents and confidentiality were guaranteed. Approval of Ethical Committee of The Scientific Research in Tanta Faculty of Medicine was obtained before starting the study.

\section{Results:}

Basic characters of the study participants: The study included 418 students (148 male and 270 female), their mean age was $22.15 \pm 1.266$ years, $45 \%$ of them were $5^{\text {th }}$ year students, $28.2 \%$ were $6^{\text {th }}$ year students, and $26.8 \%$ were house officers. The majority of the participants $(85.2 \%)$ had not received any previous training regarding patient safety). (table 1)

Perception regarding patient safety: Table (), Table (2), and Figure (): About one-third of the participants $(57.2 \%)$ had "poor" grade in total knowledge score, $57.2 \%$ had "fair" grade, and only $9.1 \%$ had "good" grade. The average total knowledge score of the study participants was $58.15 \pm 12.48$.

Near two-thirds $(64.7 \%)$ of students (both $5^{\text {th }}$ and $6^{\text {th }}$ years) and about onehalf of house officers (48.2\%) had "low knowledge" about "Characteristics of successful error reporting systems "with a statistically significant difference $(\mathrm{p}=0.000) .57 .2 \%$ of students and $37.5 \%$ of house officers had "low knowledge" about "How to report an error?", and the difference was statistically significant $(\mathrm{p}=0.000)$.

More than one-half $(55.5 \%)$ of the students rated their knowledge level as
Table (1): Characteristics of the study participants

\begin{tabular}{|c|c|c|}
\hline Character & $N(418)$ & $\%$ \\
\hline Age & \multicolumn{2}{|c|}{$\begin{array}{c}22.15 \pm 1.266 \\
\text { years }\end{array}$} \\
\hline \multicolumn{3}{|l|}{ Grade } \\
\hline $5^{\text {th }}$ year & 188 & 45.0 \\
\hline $6^{\text {th }}$ year & 118 & 28.2 \\
\hline House officer & 112 & 26.8 \\
\hline \multicolumn{3}{|l|}{ sex } \\
\hline male & 148 & 35.4 \\
\hline female & 270 & 64.6 \\
\hline \multicolumn{3}{|l|}{ Previous training } \\
\hline No & 356 & 85.2 \\
\hline Yes & 62 & 14.8 \\
\hline \multicolumn{3}{|l|}{ Place of training } \\
\hline Students`organized training & 22 & 35.5 \\
\hline Faculty workshop & 10 & 16.1 \\
\hline Hospital training & 14 & 22.6 \\
\hline Others & 16 & 25.8 \\
\hline
\end{tabular}

"low" regarding "How to analyse a case to find the cause of a medical error ".

Also, more than one-half $(54.5 \%)$ of the students reported their "low knowledge" about" Ways of speaking up about the error?"

The highest percentage of self-rated "high knowledge" level among students was $23.5 \%$ concerning "Awareness of adverse outcomes to errors in medicine".

Comparison of mean squares of knowledge on patient safety of the study participants revealed a statistically significant difference $(\mathrm{p}<0.001)$.

Attitude towards patient safety items: 
), and ( Table

Figure (): More than one-half $(53.1 \%)$ of the participants had positive attitude towards various patient safety issues. The average total attitude score of the study participants was $51.50 \pm 8.43$.

The majority of both students and house officers "agreed" that "Patient safety is a global problem" $(78.1 \%$, and $69.6 \%$ respectively). The majority of both groups $(75.8 \%$, and $76.8 \%$ respectively), "agreed" that "Being an effective team player is important to prevent incidents". "Learning from mistakes can prevent incidents" item had the "agreement" of $72.5 \%$ of students, and $65.2 \%$ of house officers. The majority of the participants also "agreed" that " After an error occurs, an effective strategy is to work harder and to be more careful $(80.4 \%$, and $73.2 \%$ among students and house officers; respectively)."Planning to make a point of learning from the mistakes of others" was "agreed" upon by the majority of the participants $(82.4 \%$, and $73.2 \%$ among students and house officers; respectively). Both students and house officers had high percent of "agreement" regarding the concept that "Physicians should routinely spend part of their professional time working to improve patient care" $(76.1 \%$, and $66.1 \%$ respectively). Near to three-quarters of students $(73.5 \%)$ think that" poorly designed systems and other factors contribute to errors in the health-care system" compared to $69.6 \%$ of house officers. Most of the students $(81.0 \%)$ "agreed" that they" Do not hesitate to change practice habits to improve patient safety", while $64.3 \%$ of house officers agreed upon that. However, the differences in most of the attitude items were not statistically significant, and comparison of mean squares of attitude regarding patient safety of the study participants revealed a non-statistically significant difference $(\mathrm{p}=0.584)$.

\section{Inclusion of patient safety issues into} medical curriculum:

Table

(3): $\quad$ Undergraduate students showed more interest towards inclusion of patient safety issues into their medical curriculum as the majority of them showed higher percentage of agreement on all items regarding this issue than house officers (who also showed high percentages of agreement) while only lower percent of the participants $(26.1 \%$ $\%)$ agreed that the had a good understanding of patient safety issues because of their undergraduate medical training (36.3\% of students, and $43.8 \%$ of house officers).

\section{Discussion}

Patient safety is still a relatively new concept, especially in the context of Egyptian medical culture. It is strategically important for a successful plan for patient safety in the future to focus on attitudes and knowledge of medical and paramedical students, which is necessary for making cultural changes sustainable. ${ }^{21,22}$

Patient safety is one of the key components and considered as of one of the core competencies of The Accreditation Council for Graduate Medical Education (ACGME), which is system-based care (SBC). It can be defined as the overall role and responsibility of the healthcare system to avoid harm to patients and provide highquality care. $^{23}$

Actually, medical students were shown to be valuable participants in ensuring patient safety specifically when they are given the opportunities and appropriate training. ${ }^{25}$

In this study, an interestingly high percent $(85.2 \%)$ of the participants had not received any previous training 
regarding patient safety, and $26.1 \%$ of them reported that they don't have good understanding of patient safety issues because of their undergraduate medical training, which is much lower than the results of who Blasiak, et al. $2014^{25}$ at the University of North Carolina (UNC), School of Medicine. who reported that more than $79 \%$ of students reporting previous effective patient safety education, and this difference may be attributed to variation of the contents of medical curricula across different medical schools.

In the present study, the mean knowledge score of the participants was $58.15 \% \pm 12.48$, which is nearly the same of the results of a study of residents and medical students at Harvard Medical School which reported patient safety knowledge as $58.4 \% \pm 15.5 \%$, and the results are also similar to that was reported by Blasiak, et al. 2014 who reported the average knowledge score as $56 \% \pm 25 \%$, however we didn't use the same questionnaire and scoring for patient safety knowledge items used in these two studies. ${ }^{23,26}$

In our study, $64.7 \%$ of students reported having "low knowledge" about "Characteristics of successful error reporting systems", and $57.2 \%$ of them had "low knowledge" about "How to report an error?" which is similar to the results of many studies from other countries in several respects. e.g., The study in UK by Flin et al., 2009 which reported that the majority of year 1 medical students reported 'medium low' levels of knowledge of error and patient safety issues, a study in US by Moskowitz et al., suggests that students are uncertain about what defines an error. $^{27,28}$

Similarly, Li et al., 2012 found that responses to items about the level of patient safety knowledge were negative, especially for the items 'Different types of medical error?' and 'How to report an error?'. ${ }^{29}$ This students` defective knowledge in the different studies may be attributed to lack of medical curricula for this topic.

In this study, $53.1 \%$ of the participants had a positive attitude to patient safety issues, which also coincides with $\mathrm{Li}$ et al., who reported that medical students' attitudes to good patient safety practices were generally positive. $^{28}$ The majority of our study participants considered "patient safety as a global problem", which is in line with Almaramhy et al., 2012, who reported an agreement of $60.7 \%$ of his study participants upon this concept. However, this percentage is considered to be low when compared to the agree attitude of over $90 \%$ reported in Hong Kong among medical students..$^{30,31}$ The results of this study revealed agreeability of the majority of participants that "Learning from mistakes can prevent incidents", and they "Plan to make a point of learning from the mistakes", and they believe that "Physicians should routinely spend part of their professional time working to improve patient care". These finding are similarly reported by Leung and Patil , 2010, Li et al., 2012, and Shah et al., 2015. ${ }^{14,30,32}$ The vast majority of our study participants agreed upon "teaching and training students about patient safety should be an important priority in medical students training", which is similarly reported by Almaramhy et al., 2012 who stated that one of the main findings arising from his study was the agreeability of the majority of the study participants towards teaching patient safety on the level of undergraduate curriculum. $^{29}$

Of great concern, the findings of the present study revealed that the most of the participants had an agreeable opinion regarding inclusion of patient safety issues into medical curriculum, this was in agreement with Almaramhy et al., 2012, and Shaht, et al., 2015 who reported that the vast majority of the students in their studies had a highly 
supportive opinion for inclusion of patient safety into medical curriculum. $^{29,14}$ Another study suggested that patient safety and medical fallibility curriculum affects the knowledge, skills, and attitudes of medical students. ${ }^{33}$

The WHO Patient Safety Curriculum Guide for Medical Schools can serve as the standard guideline for developing a uniform patient safety curriculum. Furthermore, to make the teaching of patient safety effective and fit for purpose, the theory has to be linked to real practice by applying the human factor approach in order to have a positive impact on students' future clinical performance. ${ }^{34,35}$

\section{Conclusion}

The present study revealed that medical undergraduates in Tanta faculty of medicine have a low to medium grasp of knowledge skills, and attitudes toward patient safety, but still lacking the appropriate level they demonstrated good willingness to learn more about it. Highly agreeable opinion about inclusion of patient safety issues into medical curriculum is present.

\section{Recommendations}

Early establishment of formal undergraduate curriculum on patient safety and maintaining this change in health care culture is essential to improve the quality of service and to escape medical error from the start of their medical careers. We recommend implementation of the Patient Safety Curriculum Guide developed by WHO in all medical institutions.

\section{Study limitations}

This main limitation of our study that the data was self- reported and therefore exposed to recall bias. Second limitation that it was conducted on two academic years students and house officers in one medical school that may interfere with generalizability of results, therefore additional studies are necessary to incorporate sample representative to students in all levels in different medical schools.

\section{Conflicts of interest}

Authors declare no conflicts of interest.

\section{References}

1. WHO. Patient Safety Curriculum Guide. Multi-professional Edition. Online 2011 Cited 2013 Sep 21. Available from URL: http://whqlibdoc.who.int /publications/ 2011/9789241501958_eng.pdf. coated from Pakistan study

2. Nieva VF, Sorra J. Safety culture assessment: a tool for improving patient safety in healthcare organizations. Quality and Safety in Health Care. 2003;12(suppl 2):ii17-23.

3. Reason J. Human error: models and management. Western Journal of Medicine. 2000;172(6):393.

4. Mustahsan SM, Ali SM, Khalid F, Ali AA, Ahmed H, Hashmi SA, Syedain M, Feroz F. Sleep deprivation and its consequences on house officers and postgraduate trainees. JPMA. The Journal of the Pakistan Medical Association. 2013;63(4):540-3.

5. Thomas EJ, Lipsitz SR, Studdert DM, Brennan TA. The reliability of medical record review for estimating adverse event rates. Annals of Internal Medicine. 2002;136(11):812-6.

6. Leape LL. Scope of problem and history of patient safety. Obstetrics and gynecology clinics of North America. 2008;35(1):1-0.

7. de Vries EN, Ramrattan MA, Smorenburg SM, Gouma DJ, Boermeester MA. The incidence and nature of in-hospital adverse events: a systematic review. Quality and safety in health care. 2008;17(3):216-23.

8. Andermann A, Ginsburg L, Norton P, Arora N, Bates D, Wu A, Larizgoitia I, Patient Safety Research Training and Education Expert Working Group of WHO Patient Safety. Core competencies for patient safety research: a cornerstone 
for global capacity strengthening. BMJ quality \& safety. 2011;20(1):96-101.

9. Sorensen R, Iedema R, Piper D, Manias E, Williams A, Tuckett A. Health care professionals' views of implementing a policy of open disclosure of errors. Journal of health services research \& policy. 2008;13(4):227-32.

10. Naveh E, Katz-Navon T, Stern Z. Treatment errors in healthcare: a safety climate approach. Management Science. $2005 ; 51(6): 948-60$.

11. Hofmann D, Mark A. An investigation of the relationship between safety climate and medication errors as well as other nurse and patient outcomes. Personnel Psychol 2006;59:847-69.

12. Zohar D, Livne Y, Tenne-Gazit O et al. Healthcare climate: a framework for measuring and improving patient safety. Crit Care Med 2007;35:1312-7.

13. Shojania KG, Duncan BW, McDonald KM et al. Safe but sound: patient safety meets evidence-based medicine. JAMA 2002;288:508-13.

14. Shah N, Jawaid M, Shah N, Ali SM. Patient safety: Perceptions of Medical Students of Dow Medical College, Karachi. JPMA. The Journal of the Pakistan Medical Association. 2015;65(12):1261-5.

15. Flotta D, Rizza P, Bianco A, Pileggi C, Pavia M. Patient safety and medical errors: knowledge, attitudes and behavior among Italian hospital physicians. International Journal for Quality in Health Care. 2012:mzs014.

16. Brasaite I, Kaunonen M, Martinkenas A, Suominen T. Health care professionals' attitudes regarding patient safety: cross-sectional survey. BMC research notes. 2016;9(1):177.

17. Nabilou B, Feizi A, Seyedin H. Patient safety in medical education: Students' perceptions, knowledge and attitudes. PloS one. 2015;10(8):e0135610.

18. Azimi L, Tabibi SJ, Maleki MR, Nasiripour AA, Mahmoodi M. Influence of training on patient safety culture: a nurse attitude improvement perspective. International Journal of Hospital Research. 2012;1(1):51-6.

19. Walton $M$, Woodward $H$, Van Staalduinen S, et al. The WHO patient safety curriculum guide for medical schools. Qual Saf Health Care. 2010;19(6):542-546.

20. DesHarnais SI, Nash DB. Reforming way medical students and physicians are taught about quality and safety. Mt Sinai J Med. 2011;78(6):834-841.

21. Swick HM, Szenas P, Danoff D, Whitcomb ME. Teaching professionalism in undergraduate medical education. JAMA: the journal of the American Medical Association. 1999; 282(9):830-2.

22. Carruthers S, Lawton R, Sandars J, Howe A, Perry M. Attitudes to patient safety amongst medical students and tutors: Developing a reliable and valid measure. Medical teacher. 2009; 31(8):e370-

23. Kerfoot BP, Conlin PR, Travison T, McMahon GT. Patient Safety

24. Knowledge and Its Determinants in Medical Trainees. J Gen Intern Med. 2007; 22: 1150-4.

25. Seiden SC, Galvan C, Lamm R. Role of medical students in preventing patient harm and enhancing patient safety. Qual Saf Health Care 2006;15:272-6.

26. Blasiak RC, Stokes CL, Meyerhoff KL, Hines RE, Wilson LA, Viera AJ. A cross-sectional study of medical students' knowledge of patient safety and quality improvement. North Carolina medical journal. 2014;75(1):15-20.

27. Flin R, Patey R, Jackson J, Mearns $\mathrm{K}$, Dissanayaka U. Year 1 medical undergraduates?knowledge of and attitudes to medical error. Medical Education 2009; 43(12):1147-55.

28. Moskowitz E, Veloski JJ, Fields SK, Nash DB. Development and evaluation of a 1-day interclerkship program for medical students on medical errors and patient safety. American Journal of Medical Quality 2007; 22(1): 13-7. 
29. Li L, Duan Y, Chen P, Li J, Mao X, Barraclough BH, Zhang M. Knowledge, skills, and attitudes of medical students to patient safety: a cross- sectional pilot investigation in China. Journal of Evidence- Based Medicine. 2012 Aug 1;5(3):124-33.

30. Almaramhy H, Al-Shobaili H, ElHadary K, Dandash K. Knowledge and attitude towards patient safety among a group of undergraduate medical students in Saudi Arabia. International journal of health sciences. 2012;5(1).

31. Leung Gk and Patil NG. Patient safety in the undergraduate curriculum: medical students' perception. Hong Kong Med J 2010; 16 (2): 101-5.

32. Li L, Duan Y, Chen P, Li J, Mao X, Barraclough BH, Zhang M. Knowledge, skills, and attitudes of medical students to patient safety: a cross- sectional pilot investigation in China. Journal of Evidence- Based Medicine. 2012 Aug 1;5(3):124-33.

33. Madigosky WS, Headrick LA, Nelson K, Cox KR, Anderson T. Changing and sustaining medical students' knowledge, skills, and attitudes about patient safety and medical fallibility. Academic Medicine 2006; 81(1): 94-101.

34. Nie Y, Li L, Duan Y, Chen P, Barraclough BH, Zhang M, Li J. Patient safety education for undergraduate medical students: a systematic review. BMC Med Educ. 2011; 14: 11-33.

35. Armitage G, Cracknell A, Forrest K, Sandars J. Twelve tips for implementing a patient safety curriculum in an undergraduate programme in medicine. Med Teach. 2011; 33: 535-40 
Table (2):Participants self-rating knowledge level about patient safety concepts

\begin{tabular}{|c|c|c|c|c|c|c|c|c|c|c|c|c|c|c|}
\hline \multirow[t]{3}{*}{ Knowledge concepts } & \multicolumn{2}{|c|}{$(n=306)$} & \multicolumn{4}{|c|}{ Undergraduate students } & \multicolumn{6}{|c|}{$(n=112) \quad$ House officers } & \multirow[t]{3}{*}{$\chi^{2}$} & \multirow[t]{3}{*}{$\mathbf{p}$} \\
\hline & \multicolumn{2}{|c|}{$\begin{array}{l}\text { Low } \\
\text { knowledge }\end{array}$} & \multicolumn{2}{|c|}{$\begin{array}{l}\text { Medium } \\
\text { knowledge }\end{array}$} & \multicolumn{2}{|c|}{$\begin{array}{l}\text { High } \\
\text { knowledge }\end{array}$} & \multicolumn{2}{|c|}{$\begin{array}{l}\text { Low } \\
\text { knowledge }\end{array}$} & \multicolumn{2}{|c|}{$\begin{array}{l}\text { Medium } \\
\text { knowledge }\end{array}$} & \multicolumn{2}{|c|}{$\begin{array}{l}\text { High } \\
\text { knowledge }\end{array}$} & & \\
\hline & $\mathbf{n}$ & $\%$ & $\mathbf{n}$ & $\%$ & $\mathbf{n}$ & $\%$ & $\mathbf{n}$ & $\%$ & n & $\%$ & $\mathbf{n}$ & $\%$ & & \\
\hline 1.Patient safety standards & 111 & 36.3 & 175 & 57.2 & 20 & 6.5 & 26 & 23.2 & 62 & 55.4 & 24 & 21.4 & 21.59 & $<0.001 *$ \\
\hline 2. What should happen if an error was made? & 146 & 47.7 & 138 & 45.1 & 22 & 7.2 & 27 & 24.1 & 60 & 53.6 & 25 & 22.3 & 28.98 & $<0.001 *$ \\
\hline 3. Different types of medical error & 130 & 42.5 & 153 & 50.0 & 23 & 7.5 & 22 & 19.6 & 65 & 58.0 & 25 & 22.3 & 28.43 & $<0.001^{*}$ \\
\hline $\begin{array}{l}\text { 4. Incidence/frequency of medical mistakes/errors } \\
\text { made by physicians }\end{array}$ & 115 & 37.6 & 161 & 52.6 & 30 & 9.8 & 27 & 24.1 & 64 & 57.1 & 21 & 18.8 & 10.07 & $0.006^{*}$ \\
\hline 5. Factors contributing to medical errors & 105 & 34.3 & 167 & 54.6 & 34 & 11.1 & 24 & 21.4 & 68 & 60.7 & 20 & 17.9 & 7.85 & $0.020^{*}$ \\
\hline $\begin{array}{l}\text { 6. Awareness of adverse outcomes to errors in } \\
\text { medicine }\end{array}$ & 87 & 28.4 & 147 & 48.0 & 72 & 23.5 & 27 & 24.1 & 46 & 41.1 & 39 & 34.8 & 5.36 & 0.069 \\
\hline 7. Factors influencing patient safety? & 89 & 29.1 & 159 & 52.0 & 58 & 19.0 & 16 & 14.3 & 56 & 50.0 & 40 & 35.7 & 17.33 & $<0.001^{*}$ \\
\hline 8. Ways of speaking up about error? & 167 & 54.6 & 97 & 31.7 & 42 & 13.7 & 36 & 32.1 & 52 & 46.4 & 24 & 21.4 & 16.57 & $<0.001 *$ \\
\hline 9. How to report an error? & 175 & 57.2 & 99 & 32.4 & 32 & 10.5 & 42 & 37.5 & 41 & 36.6 & 29 & 25.9 & 19.95 & $<0.001^{*}$ \\
\hline $\begin{array}{l}\text { 10. Characteristics of successful error reporting } \\
\text { systems }\end{array}$ & 198 & 64.7 & 93 & 30.4 & 15 & 4.9 & 54 & 48.2 & 39 & 34.8 & 19 & 17.0 & 18.88 & $<0.001 *$ \\
\hline $\begin{array}{l}\text { 11. How to analyze a case to find the cause of a medical } \\
\text { error }\end{array}$ & 170 & 55.6 & 112 & 36.6 & 24 & 7.8 & 42 & 37.5 & 53 & 47.3 & 17 & 15.2 & 12.16 & $0.002 *$ \\
\hline 12. Understanding and managing clinical risk & 138 & 45.1 & 137 & 44.8 & 31 & 10.1 & 28 & 25.0 & 50 & 44.6 & 34 & 30.4 & 29.91 & $<0.001^{*}$ \\
\hline
\end{tabular}

* Statistically significant 
Table (3): Participants attitude towards patient safety items

\begin{tabular}{|c|c|c|c|c|c|c|c|c|c|c|c|c|c|c|}
\hline \multirow[t]{3}{*}{ Attitude items } & \multicolumn{6}{|c|}{ Undergraduate students $(n=306)$} & \multicolumn{6}{|c|}{ House officers $(n=112)$} & \multirow[t]{3}{*}{$\chi^{2}$} & \multirow[t]{3}{*}{$\mathbf{p}$} \\
\hline & \multicolumn{2}{|c|}{ Agree } & \multicolumn{2}{|c|}{ Neutral } & \multicolumn{2}{|c|}{ Disagree } & \multicolumn{2}{|c|}{ Agree } & \multicolumn{2}{|c|}{ Neutral } & \multicolumn{2}{|c|}{ Disagree } & & \\
\hline & $\mathbf{n}$ & $\%$ & n & $\%$ & n & $\%$ & $\mathbf{n}$ & $\%$ & n & $\%$ & n & $\%$ & & \\
\hline 1. Patient safety is a global problem & 239 & 78.1 & 47 & 15.4 & 20 & 6.5 & 78 & 69.6 & 24 & 21.4 & 10 & 8.9 & 3.21 & 0.201 \\
\hline 2. Making errors in medicine cannot be prevented & 90 & 29.4 & 113 & 36.9 & 103 & 33.7 & 46 & 41.1 & 32 & 28.6 & 34 & 30.4 & 5.35 & 0.069 \\
\hline $\begin{array}{l}\text { 3. It is impossible to provide safe, high-quality care while being } \\
\text { efficient }\end{array}$ & 88 & 28.8 & 104 & 34.0 & 114 & 37.3 & 33 & 29.5 & 26 & 23.2 & 53 & 47.3 & 5.15 & 0.076 \\
\hline 4. Being an effective team player is important to prevent incidents & 232 & 75.8 & 60 & 19.6 & 14 & 4.6 & 86 & 76.8 & 21 & 18.8 & 5 & 4.5 & 0.04 & 0.979 \\
\hline 5. If I keep learning from my mistakes, I can prevent incidents & 222 & 72.5 & 62 & 20.3 & 22 & 7.2 & 73 & 65.2 & 24 & 21.4 & 15 & 13.4 & 4.25 & 0.119 \\
\hline $\begin{array}{l}\text { 6. Competent physicians do not make medical errors that harm } \\
\text { patients }\end{array}$ & 70 & 22.9 & 138 & 45.1 & 98 & 32 & 40 & 35.7 & 40 & 35.7 & 32 & 28.6 & 7.15 & $0.028^{*}$ \\
\hline 7. Willing to report errors whether or not patient was harmed & 170 & 55.6 & 102 & 33.3 & 34 & 11.1 & 65 & 58.0 & 31 & 27.7 & 16 & 14.3 & 1.6 & 0.448 \\
\hline 8. Willing to share information about clinical errors & 198 & 64.7 & 78 & 25.5 & 30 & 9.8 & 71 & 63.4 & 30 & 26.8 & 11 & 9.8 & 0.08 & 0.963 \\
\hline $\begin{array}{l}\text { 9. After an error occurs, an effective strategy is to work harder and } \\
\text { to be more careful }\end{array}$ & 246 & 80.4 & 47 & 15.4 & 13 & 4.2 & 82 & 73.2 & 22 & 19.6 & 8 & 7.1 & 2.82 & 0.245 \\
\hline 10. I plan to make a point of learning from the mistakes of others & 252 & 82.4 & 44 & 14.4 & 10 & 3.3 & 82 & 73.2 & 22 & 19.6 & 8 & 7.1 & 5.16 & 0.076 \\
\hline $\begin{array}{l}\text { 11. Physicians should routinely spend part of their professional time } \\
\text { working to improve patient care }\end{array}$ & 233 & 76.1 & 56 & 18.3 & 17 & 5.6 & 74 & 66.1 & 27 & 24.1 & 11 & 9.8 & 4.75 & 0.093 \\
\hline $\begin{array}{l}\text { 12. I think that poorly designed systems and other factors contribute } \\
\text { to errors in the health-care system }\end{array}$ & 225 & 73.5 & 70 & 22.9 & 11 & 3.6 & 78 & 69.6 & 24 & 21.4 & 10 & 8.9 & 4.89 & 0.087 \\
\hline 13. Support and not blame peers who make un intentional errors & 122 & 39.9 & 117 & 38.2 & 67 & 21.9 & 41 & 36.6 & 46 & 41.4 & 25 & 22.3 & 0.40 & 0.819 \\
\hline $\begin{array}{l}\text { 14. Do not hesitate to change practice habits to improve patient } \\
\text { safety }\end{array}$ & 248 & 81.0 & 47 & 15.4 & 11 & 3.6 & 72 & 64.3 & 26 & 23.2 & 14 & 12.5 & 16.78 & $0.000^{*}$ \\
\hline 15. Likely to disclose an error to the faculty or patient & 123 & 40.2 & 132 & 43.1 & 51 & 16.7 & 55 & 49.1 & 42 & 37.5 & 15 & 13.4 & 2.71 & 0.258 \\
\hline
\end{tabular}

* Statistically significant 
Table (2): Comparison of Mean Squares of knowledge on Patient Safety concepts and Attitude to Patient Safety items $(n=418)$.

\begin{tabular}{|c|c|c|c|c|c|c|}
\hline & 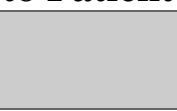 & $\begin{array}{l}\text { Sum of } \\
\text { Squares }\end{array}$ & df & $\begin{array}{l}\text { Mean } \\
\text { Square }\end{array}$ & $\mathbf{F}$ & Sig. \\
\hline \multirow[t]{3}{*}{ Attitude Grade } & $\begin{array}{l}\text { Between } \\
\text { Groups }\end{array}$ & 0.075 & 1 & 0.075 & 0.301 & 0.584 \\
\hline & $\begin{array}{l}\text { Within } \\
\text { Groups }\end{array}$ & 104.020 & 416 & 0.250 & & \\
\hline & Total & 104.096 & 417 & & & \\
\hline \multirow[t]{3}{*}{$\begin{array}{l}\text { Knowledge } \\
\text { Grade }\end{array}$} & $\begin{array}{l}\text { Between } \\
\text { Groups }\end{array}$ & 18.171 & 1 & 18.171 & 55.807 & $0.000^{*}$ \\
\hline & $\begin{array}{l}\text { Within } \\
\text { Groups }\end{array}$ & 135.449 & 416 & 0.326 & & \\
\hline & Total & 153.620 & 417 & & & \\
\hline
\end{tabular}

* Statistically significant 
Table (3): Participants`opinion about inclusion of patient safety issues into medical curriculum

\begin{tabular}{|c|c|c|c|c|c|c|c|c|c|c|c|c|c|c|}
\hline \multirow[t]{3}{*}{ Item } & \multicolumn{6}{|c|}{$\begin{array}{l}\text { Undergraduate students } \\
(n=306)\end{array}$} & \multicolumn{6}{|c|}{$\begin{array}{l}\text { House officers } \\
(n=112)\end{array}$} & \multirow[t]{3}{*}{$\chi^{2}$} & \multirow[t]{3}{*}{$\mathbf{p}$} \\
\hline & \multicolumn{2}{|c|}{ Agree } & \multicolumn{2}{|c|}{ Neutral } & \multicolumn{2}{|c|}{ Disagree } & \multicolumn{2}{|c|}{ Agree } & \multicolumn{2}{|c|}{ Neutral } & \multicolumn{2}{|c|}{ Disagree } & & \\
\hline & $\mathbf{n}$ & $\%$ & n & $\%$ & $\mathbf{n}$ & $\%$ & n & $\%$ & n & $\%$ & $\mathbf{n}$ & $\%$ & & \\
\hline $\begin{array}{l}\text { 1. Teaching students about patient safety should be an } \\
\text { important priority in medical students training. }\end{array}$ & 274 & 89.5 & 27 & 8.8 & 5 & 1.6 & 87 & 77.7 & 19 & 17.0 & 6 & 5.4 & 10.59 & $0.005^{*}$ \\
\hline $\begin{array}{l}\text { 2. Learning how to improve patient safety is an appropriate } \\
\text { use of time in medical school. }\end{array}$ & 249 & 81.4 & 49 & 16.0 & 8 & 2.6 & 249 & 81.4 & 49 & 16.0 & 8 & 2.6 & 6.22 & $0.045^{*}$ \\
\hline 3. You would like to receive further teaching on patient safety. & 245 & 80.1 & 50 & 16.3 & 11 & 3.6 & 85 & 75.9 & 18 & 16.1 & 9 & 8.0 & 3.65 & 0.168 \\
\hline $\begin{array}{l}\text { 4. Effective team working and communication skills should be } \\
\text { included in medical curriculum }\end{array}$ & 250 & 81.7 & 42 & 13.0 & 14 & 4.6 & 81 & 72.3 & 21 & 18.8 & 10 & 8.9 & 4.99 & 0.082 \\
\hline 5. I would like to know how to report an error & 232 & 75.8 & 63 & 20.6 & 11 & 3.6 & 75 & 67.0 & 27 & 24.1 & 10 & 8.9 & 5.99 & 0.050 \\
\hline 6. I should learn how to find the cause of an error. & 241 & 78.8 & 50 & 16.3 & 15 & 4.9 & 88 & 78.6 & 14 & 12.5 & 10 & 8.9 & 3.01 & 0.222 \\
\hline $\begin{array}{l}\text { 7. I should learn how to disclose an error to a patient or faculty } \\
\text { member. }\end{array}$ & 215 & 70.3 & 72 & 23.5 & 19 & 6.2 & 77 & 68.8 & 30 & 26.8 & 5 & 4.5 & 0.818 & 0.664 \\
\hline $\begin{array}{l}\text { 8. Learning about patient safety issues before graduation will } \\
\text { enable me to become a more effective doctor }\end{array}$ & 247 & 80.7 & 46 & 15.0 & 13 & 4.2 & 73 & 65.2 & 29 & 25.9 & 10 & 8.9 & 11.24 & $0.004^{*}$ \\
\hline $\begin{array}{l}\text { 9. I have a good understanding of patient safety issues because } \\
\text { of my undergraduate medical training. }\end{array}$ & 111 & 36.3 & 107 & 35.0 & 88 & 28.8 & 49 & 43.8 & 42 & 37.5 & 12 & 18.8 & 4.49 & 0.106 \\
\hline $\begin{array}{l}\text { 10. Infection control and medication Safety are important } \\
\text { parts of patient safety that should be incorporated in medical } \\
\text { curriculum }\end{array}$ & 254 & 83.0 & 37 & 12.1 & 15 & 4.9 & 89 & 79.5 & 14 & 12.5 & 9 & 8.0 & 1.54 & 0.463 \\
\hline
\end{tabular}

* Statistically significant 


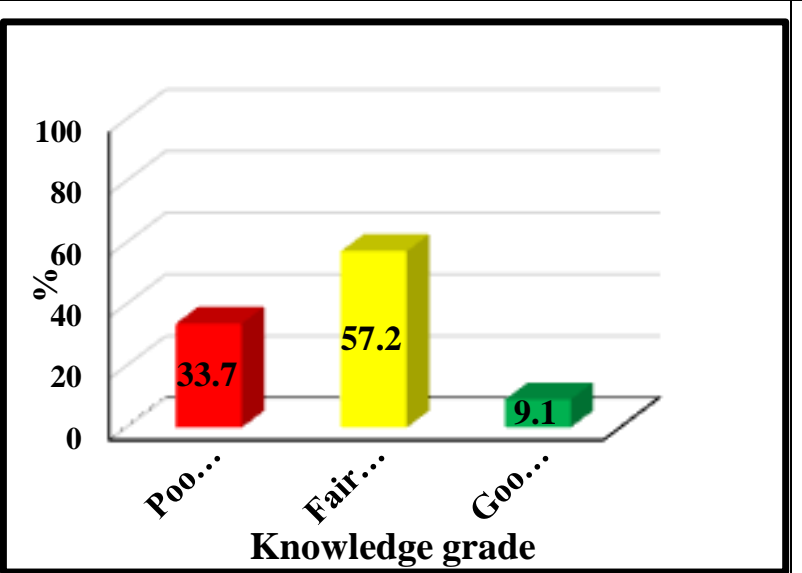

Figure (1): Distribution of the participants according to their total knowledge score

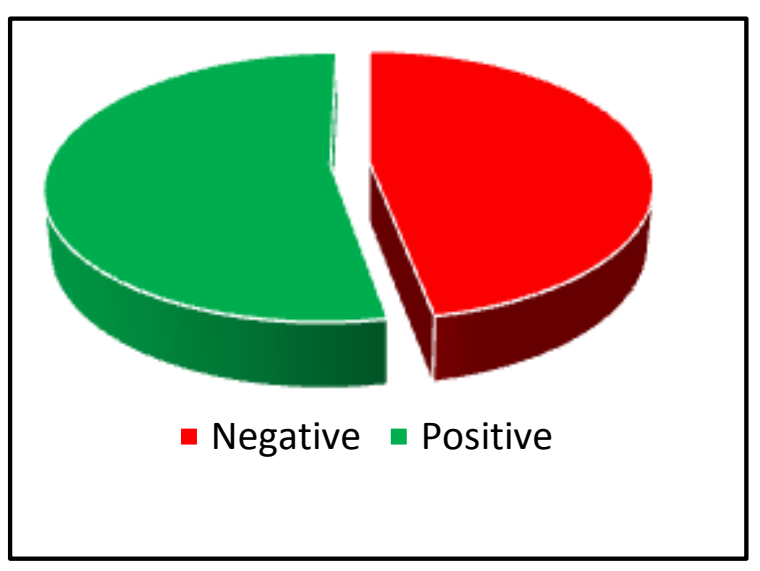

Figure (2): Distribution of the participants according to their total attitude score regarding patient safety 